\title{
The Anthropology of Uncertainty: Magic, Witchcraft and Risk and Forensic Implications
}

\section{Simon Dein}

Department of Theology and Religion, Durham University, UK

"Corresponding author: Dein S, Lecturer in Spirituality, Department of Theology and Religion, Durham University, UK, Tel: +44 (0) 1913341612 ; Fax: +44 (0) 191334 1615; E-mail:simon.dein@durham.ac.uk

Received date: 17 June 2016; Accepted date: 24 June 2016; Published date: 30 June 2016

Copyright: ( 2013 Dein S. This is an open-access article distributed under the terms of the Creative Commons Attribution License, which permits unrestricted use, distribution, and reproduction in any medium, provided the original author and source are credited.

\section{Abstract}

This paper examines the Anthropology of Uncertainty. After a discussion of what constitutes uncertainty I examine various ways of dealing with this in non-western cultures: witchcraft, magic and religion. I then move onto a discussion of contemporary aspects of risk in Western societies. I discuss its historical emergence and the relationship between risk, sin and taboo. Witchcraft, religion and risk all provide explanatory framework for misfortune. Witchcraft also involves issues of accountability. This is similarly the case for risk. Both witchcraft and risk have forensic implications. I illustrate this by the work of Mary Douglas.

Keywords: Anthropology; Forensic implications

\section{Introduction}

All societies have to cope with uncertainty, the fact that the future is unpredictable, and to account for past misfortunes. Anthropological theory has generally privileged the regularities of everyday life, paying less attention to irregular events that disrupt the social order. Uncertainty and irregularity run closely together. Cooper and Pratten [1] assert that uncertainty exists in a complex semantic field, associated with a family of concepts including insecurity, indeterminacy, risk, ambiguity, ambivalence and obscurity mixed with confusion; chance possibility. These authors argue that uncertainty has become a dominant trait, an inevitable force in the subjective experience of life in contemporary American societies. While culture impacts upon the ways uncertainty is dealt with, coping strategies often invoke some issues of accountability asking who is responsible for this misfortune.

Haram and Yamba [2] mention that in anthropology the term uncertainty is often used in an undefined manner to imply unpredictable outcomes, often the negative kind, rendering life precarious. Some would however maintain that it is this unpredictability that makes life a challenging drama. Boholm [3] notes that uncertainty has to do with what is unpredicted in life, the odd possibilities and irregular occurrences. When uncertainty has a positive flavour we speak of 'luck' or good 'fortune' and when uncertainty is tainted by dismal or catastrophic expectations we speak of 'risk'. She further argues [4] that while culture refers to shared knowledge in society steering expectations to what is normal, valid and customary, contingency refers to the fact that human events and actions are unpredictable.

The term uncertainty commonly refers to accidents, the inset of bad fortune, severe illness, sudden death and other contingent events, which are neither predictable nor exist within ones sphere of control. We include here economic insecurity, reproductive failure and threatened health. It is generic to the human condition. Cultures differ significantly in how they attribute cause to particular events. These may include accident, chance, providence or events occurring on a count of the agency of some malevolent force. Explanation spurs on management: medicine, technology, rituals and magic. Divination may reveal causes of misfortune, ranging from ancestors and spirits to sorcerers. Blame is often attributed to some person or supernatural entity. Sufferers and their families will then experiment with a variety of remedial measures, including pharmaceuticals, sorcery antidotes, and sacrifices. But remedies often fail, and doubt and uncertainty persist.

There is a long anthropological legacy pertaining to how individuals deal with uncertainty from classical studies of misfortune to more recent studies of risk and uncertainty [5-8]. Furthermore the management of uncertainty has become an important theme in sociological studies of risk taking society [9]. Many anthropologists assert that religion and ritual serve universal functions in coping with contingency or the 'fragility of human life' [10,11]. Religious ideas provide explanatory frameworks for contingency - the idea that events and human actions are unpredictable - and offer practical strategies for dealing with epistemic uncertainty. Both religion and ritual symbolically order contingency by means of interpretations and explanations 'founded in the transcendental realms of intentionally acting deities or supernatural agents' [4]. What appears obvious is that people are acutely aware of the uncertainties in their lives and develop strategies to deal with them. Often these are purely pragmatic.

\section{The Pragmatics of Uncertainty}

Anthropological studies demonstrate that we do need to explain unpredictable occurrences in order to manage or control them, and to prevent their future occurrence. Despite living with uncertainty, humans attempt to create a sense of security and insurance and humans are never merely the victims of fate [8]. Bourdieu's notion of illusio represents the human drive to invest in dreams and hopes either materially or symbolically as a struggle for immediate control even while simultaneously presenting as illusory [12]. That we do not submit to the inevitable is demonstrated by natural science and medicine and through attempts to intervene in destiny in other cultures. Control is always negotiated within social relations. 
Reith asserts that we live in a universe of chance. Ideas of chance, risk and luck have pre-occupied human kind for centuries, and act as a micro-chasm for the major themes in existence, freewill, determinism, reason, unreason, knowledge and belief [13]. Understanding of uncertainty is central to the understanding of how societies operate.

Actions are mediated through knowledge we share with others. By as ethnographic studies illustrate, people do not just do what their culture tells them, to do, there is rarely just one obvious thing to dothere are often diverse alternatives [8]. The management of uncertainty is dependent as much on personal history as cultural factors. In terms of illness, cure seeking attempts to conjure up a sense of order amidst the chronic uncertainties of life $[8,14]$. Much of this work on illness has focused upon narrative as a way of engaging with possibilities $[15,16]$. Patient-healer interactions are occasions whereby narratives are formed, rehearsed and enunciated. Narratives can provide a sense of order and meaning in the midst of suffering.

Richard Jenkins, Hanne Jessen and Vibeke Steffen assert that when facing questions of health and illness rational solutions and meaningful explanations may be difficult to find, and treatment efforts are often guided just as much by hope as by rational choice [17]. Evaluating the risks of illness is just one of a number of diverse ways in which human beings attempt to exert some sense of control over their lives. Sickness brings the uncertainties of existence. Health-seeking can be viewed as an attempt to create a sense of relative order in the face of the constant uncertainty of life; the responses to ill-health, however, are highly diverse and unpredictable, with people often drawing on all the alternatives potentially available. While Institutionalized medicine can be understood as the state-sponsored attempt to rationalize control of uncertainty and the creation of a predictable social environment; attempts to control, reduce or remove uncertainty may often result in the generation of further uncertainty. For example in her discussion of patients' experiences of fertility treatment in Denmark, TjørnhøjThomsen notes the extensive range of new uncertainties that are created in their encounter with reproductive technology [18]. These are driven by the inability of medical experts themselves to predict and control fertility. Contrary to what patients expect to find, biomedical knowledge is incomplete and uncertain, too.

Based on a long-term study of adversity and its social causes in Bunyole, eastern Uganda, Whyte considers the way in which people deal with uncertainties of life, such as sickness, suffering, marital problems, failure, and death [8]. She argues that the Nyole are keenly aware of the place of uncertainty and ambiguity in their social world and address adversity in a pragmatic spirit. The Nyole's world is not composed of blind certainties, and their doubting does not derive from the historically recent exposure to modernity and postmodernity. Rather the Nyole have been questioning and doubting and experimenting "all along" (p. 205). She notes how skepticism and hope cause the Nyole to inhabit a world characterized by a "subjunctive mode" (p. 24)-a mode open to possibilities. In Bunyole the ability of people to effectively control life is substantially reduced by their lack of resources. What are significant, though, are the possibility of action and the availability of practical and specific responses that can be 'tried out' to cope with uncertainty.

Caroline Bledsoe [19] applies a pragmatic theoretical stance in relation to reproductive strategies among Gambian women. There women view their reproductive career in a nonlinear fashion because of contingent life conditions that render it impossible to plan reproductive strategies in advance, in parallel with biological aging. She speaks of contingency in relation to containment and how it "implies a capacity to take action to check harmful repercussions of events, especially through cultivating social ties with those who can help in a crisis" (p. 25).

While most women in the West use contraceptives in order to avoid having children, in rural Gambia and other parts of sub-Saharan Africa, many women employ contraceptives for the opposite reasonto have as many children as possible. This ethnography explains the use of contraception by Gambian women in their mid- to late-thirties who desire additional children. Deploying ethnographic and demographic data from a three-year study in rural Gambia, she accounts for this seemingly counterintuitive fact by juxtaposing two significantly different understandings of the life course: one is a linear, Western model that equates aging and the ability to reproduce with the passage of time, the other a Gambian model that views aging as contingent on the cumulative physical, social, and spiritual hardships of personal history, especially obstetric trauma.

Johnson-Hanks' research among Cameroonian women discusses how women talk about social timing of births instead of total numbers of births [17]. Having children is not a product of an intentional act because there are many possible pathways to motherhood and one must be open to respond effectively to the contingent and surprising situations that life offers [20].

\section{Witchcraft: Causes and Accountability}

Witchcraft accusations have been studied both as explanatory models of misfortune and also as a way to address interpersonal conflicts, air grievances and to restore social relations. They always presuppose issues of accountability and to this extent are open to forensic analysis. In some instances people may be punished for their putative actions, in other instances, such as the Azande, the emphasis is on the voluntary removal of witchcraft by voluntary purgation. Accusations of witchcraft usually target vulnerable groups including women, children and the elderly and have been documented in a large number of countries across the world. Accusations of witchcraft usually target already vulnerable groups, such as women, children and the elderly, and have been documented in a large number of countries around the world.

Accusations of witchcraft usually target already vulnerable groups, such as women, children and the elderly, and have been documented in a large number of countries around the world.

Evans-Pritchard in his classic study of a traditional society in Southern Sudan discussed the ways in which the azande were able to account for every misfortune, often uniting empirical evidence, e.g. termites eating through the wood support of granary or the skill of a particular potter, with specific religious ideas such as witchcraft or sorcery [5]. For him witchcraft accounted for the particularities of misfortune. Witchcraft transcended scientific theories of cause and effect, thus providing explanations for otherwise inexplicable happenings. Systems such as witchcraft provide explanations for everything leaving no space for uncertainty. Witchcraft rather than theism is the fuel of Azande morality. Evans Pritchard emphasized the notion of accountability in his work. He argued that by focusing upon the ways that different segments of society hold each other accountable, it was possible to discern the relationship between individuals and institutions.

In Europe and North America as people adopted the belief that the world was the terrifying realm of the devil, they blamed witches for 
every misfortune. Since the devil created all the ills of the world, his agents - witches - could be blamed for them. In early modern Europe and in Salem, witchcraft accusations reflected the inequality between rural and urban regions, gender and socio-economic status [21]. In the modern global economy there are anxieties relating to the theft of children's organs and ritual murder reflecting concerns about child trafficking and migration. In Europe and the United States, allegations about the satanic abuse of children persist as media reports multiply about child abductions and horrific serial killers.

Supernatural discourses represent a distinctive way of articulating fears about the increased uncertainty found in everyday life and the insecurities of the global economy. Relatedly McNally notes that capitalist culture, as such, is saturated with representations of monsters, dismemberment, blood-draining exploitation, and the reduction of human life to mere biology and drive. These images, transfigured distortions, almost ideal-types, reflect the workings of real social processes and underscore the exploitation of human life as well as the longings of all who suffer under the impact of capital accumulation.

Anthropologists have noted that the feelings of uncertainty, insecurity, and anxiety deriving from the dangerous volatility, disorder, and opaqueness of the market are frequently articulated through the medium of popular religion, shamanism, witchcraft, and spirit possession [22]. There is evidence that accusations of witchcraft have increased in postcolonial African societies because of disenchantment with the "failed state" and neoliberal capitalism [23,24].

Moore and Sauders maintain that supernatural discourses represent a distinctive way of articulating fears about the increased uncertainty found in everyday life and the insecurities of the global economy. Through focusing on the intimate connections between magic on the one hand and the state, development, markets and media on the other, their book Magical interpretations, material realities aims to demonstrate the various and unexpected ways in which magic has become 'not only contiguous with, but constitutive' of African modernity. They underscore the ongoing presence and power of the occult imaginary, and of the intimate connection between global capitalism and local cosmology. These authors use recent ethnographic materials from across the continent to explore how witchcraft articulates with particular modern settings for example: the State in Cameroon; Pentecostalism in Malawi; the university system in Nigeria and the IMF in Ghana, Sierra Leone and Tanzania .

They raise the important the question as to why, despite the predictions of countless modernists, sources of mystic power have not diminished by the increasing influence of modernity. Far from progressively weakening under the influence of science and education, beliefs in the magical have remained central to the ways African people see contemporary realities and they note that the evolutionary paradigm of earlier theorists is thoroughly flawed in its assumptions of unilinear progress and development. Recent studies of witchcraft have made additional theoretical contributions to the existing literature by demonstrating quite convincingly that far from simply being an expression of modernity, magic and metaphysics are actually constitutive of that modernity.

As Geschiere asserts, the powers of witchcraft are ambivalent and they can easily reinvent themselves in novel situations: 'It is precisely through this ambivalence that discourses on the occult incorporate modern changes so easily' [25]. In a similar way Geschiere argues that the obsession with witchcraft in many parts of present-day Africa is not to be understood as some traditional residue. On the contrary, it is more pronounced in the more modern spheres of society. These views concur with Comaroff and Comaroff who argue that contemporary occult practices including witchcraft are neither a return to traditional practices nor a sign of backwardness [22]. Rather they are thoroughly modern manifestations of uncertainties, moral disquiet and unequal rewards and aspirations in the present moment. In a comparative, global perspective, this linking of modernity and witchcraft is not particular to Africa: in other parts of the globalized world, modern developments coincide with a proliferation of what the Comaroffs call 'the economies of the occult'

Morality, ethics and accountability in Africa are to be understood in terms of his relationships to (1) the spirit world and (2) the kinship community. African witchcraft is often seen as a matter of social diagnostics rather than one of 'belief'. Space does not allow me to deconstruct notions of witchcraft in the anthropological literature aside from stating that understandings of witchcraft need to be situated in their ethnographic and historical settings. Indeed many authors underscore the fact that local African terms are not direct translations of the English term witchcraft and can refer to both good and bad mystical forces.

Haram and Yamba discuss both the increasing uncertainty and insecurity of life in contemporary Africa and the ways that people respond, including warding off and reaching out [2]. The authors underscore the fact that witch beliefs become elaborated as explanations of failures and malaise while witch finding becomes a lucrative profession. For similar reasons Pentecostal or other fundamentalist churches grow as they teach people that life has meaning and better times are before them if only they believe. Suicide and insanity are other possible responses.

Parish notes how in Ghana 'It is in this diasporic context, marked by a pervasive sense of uncertainty, unpredictability and contestability, that anti-witchcraft shrines are popular. For her contemporary fears about witchcraft reflect moral uncertainties about identity, sociability and materialism. These ideas are expressed by means of a highly selfreflexive critique of the concepts of social admiration and transcultural consumption [26].

\section{Magic and Ritual}

Every society has developed ways of accounting for misfortune and avoiding it. Malinowski identified the significance of dangerous long sea journeys for the Trobriand Islanders and discussed the ways in which they sought to deal with these dangers through a combination of technical skill and magic. He made two important observations: First, people perceive some actions as more risky and uncertain than others and risky actions are likely to entice adjacent ritual behavior. Second, the performance of ritual actions has an effect on the likelihood of peoples' representations of success and thus the likelihood of performing such actions.

Comaroff and Comaroff assert that neoliberal capitalism encourages a world characterized by invisible class distinctions, environmental catastrophes, moral panics, social impossibilities, bitter generational antagonisms, gender conflicts, and heightened flows of people and value across both space and time. They deploy the phrase "millennial capitalism" to denote both the real timing of the economic transformation in the late 20th and early 21 st centuries, and to capture the magical, supernatural, fearful overtones associated with the turn of the millennium. Deploying ethnographic research in South Africa and 
many other parts of the world, they underscore the recent proliferation of "occult economies," magical (by way of, say, wealth-sucking zombies) and quite practical (by way of, say, extravagant Ponzi schemes) ways of gaining extreme wealth in the absence of productive labor. The term occult economy refers to the deployment of magical means for material ends or, more expansively, the conjuring of wealth by resort to inherently mysterious techniques, whose principles of operation are neither transparent nor explicable in conventional terms [23].

Recent studies suggest the efficacy of ritual in coping with uncertainty. Ainslie demonstrates how in the Eastern Cape Province of South Africa, chronic economic uncertainty has seen social relations stretched to breaking point [27]. Informants speak of a 'war between men and women'. He notes that for the most part, people in rural South Africa suffer from increased poverty. Their homestead units are becoming smaller and their offspring who are highly mobile between town and country, cannot be relied upon to support their natal homes. For the majority of these men, in their increasingly atomized, desperate move between town and rural areas, their shifting in and (increasingly permanently) out of stable employment, and in their struggles with alcohol abuse, women, money, with their offspring and with each other, the hardship of life on the periphery has become unrelenting and increasingly difficult to cope with.

While extreme poverty, death due to HIV and suspicion are highly prevalent, and the project of building the umzi (homestead) falters, hope for the future and with it, trust between people is gradually eroded. One response to such uncertainty is appeal to ritual. Through the performance of rituals invoking the ancestors and the Christian deity in various forms, Xhosa people attempt to enhance trust, secure ongoing investment in the rural homestead and maintain ties of reciprocity both among rural people and between them and their urban kin. Performing rituals allows for assessments of where the often dispersed members of this 'agnatic cluster' currently stand in relation to each other. Ceremonies have become central strategies for integrating money flows from formal redistributive sources of the state and informal reciprocal credit arrangements. It is also through the performance of these rituals that marginalized women, acting in unison, have become increasingly assertive - often in the face of a violent, rearguard opposition from men - in their efforts to exert agency over the differentiated, fragmented and fragile social and economic relationships within their homesteads and across their villages.

Buyandelgeriy explores the proliferation of previously suppressed shamanic practices among ethnic Buryats in Mongolia after the collapse of socialism in 1990 [28]. Contrary to the Buryats' expectation that shamanism would resolve the uncertainties caused by the market economy; it has created additional spiritual uncertainties. The Buryats attribute their current misfortunes to their origin spirits (ug garval), who have come back to seek revenge against their descendants for abandoning them during the socialist state's suppression of religion.

As Buryats appease their angry origin spirits to alleviate the causes of their misfortunes, they reconstruct their history, which was suppressed by state socialism. The Buryats discover meaning in recurrent misfortunes by placing them within the shifting history of their tragic past. Through shamanism, the Buryats creatively tie together their current upsets with historical oppression. In Mongolia, economic crises, other misfortunes, and fear of curses and pollution are fertile grounds for accusing a shaman of causing harm. Because shamans are held to harm, there is an urgent need for other, more powerful, shamans who can deflect such harm. It is only the formulation of Buryat spiritual and social history that renders their present misfortunes meaningful to them. This study illustrates broader anthropological concerns about the emergence of new cultural spaces and practices in former socialist and preindustrial societies currently undergoing transitions to market economies.

Poggie and Pollnac in their study of Rhode Island fishermen found that the principal function of ritual among fishermen in Southern New England is to reduce anxiety resulting from uncertainty with respect to personal safety [29]. Where the meaning of the taboo was specified by the fishermen, it was more than four times as likely to focus upon protection from danger to self as production. Of the nine high frequency taboos, representing 69 percent of the total responses, four were concerned only with personal safety in contrast to only one concerned exclusively with production. The rest had mixed functions, but it is important to note that the highest frequency taboo, 'never turn a hatch cover upside down,' was almost twice as likely to be interpreted as affecting personal safety than as affecting production. Hence, the subjective meaning attached to the taboos by the fishermen themselves tends to support the hypothesis that they function primarily to 'protect' the fishermen from physical harm. Insuring a good catch seems to be secondary to safety. This is like the 'hierarchy of life.' We must satisfy our safety needs before we do anything further.

I now move onto discussion of contemporary notions of risk in Western societies and discuss the ways in which they help deal with uncertainty while at the same time am deeply linked to issues of accountability.

\section{The Secularization of Chance: Risk and Accountability}

In Medieval times the doctrine of divine providence asserted that everything happened for a purpose and therefore every event, however insignificant, was a predetermined part of a grand design, clues to which were to be discovered in apparently random or 'chance' events [30]. Chance events were 'transcendental symbols' and space and time, having been created by God, were interdependent. The material world was a reflection of the higher cosmic order; an individual's place in the world was inflexible. Time therefore was a symbolic representation of transcendental meaning rather than a measure of duration.

Reith notes that within such a relatively closed system, an alternative set of beliefs in magic and luck coexisted that permitted the exercise of at least some degree of human agency in matters of contingency [31]. Even in this 'closed system' it was possible to influence the world by magic and witchcraft and many rituals existed to foresee and influence the future. Thomas notes that notion of lucky times was invoked to account for the vicissitudes of everyday life, and to make decisions about a future course of action. Such a cosmology reflected a conception of time as a meaningful, symbolic entity; things always occurred for a reason and it was therefore impossible to conceive of randomness. Individual, unconnected events in the present were seen as signs of providential meaning.

Divination, a popular activity in the Middle Ages, maintained belief in 'a providence that is concerned with the lot of humanity and is prepared to help man by revealing what would otherwise be unknown to them'[32]. Every significant decision was referred to prophets or diviners prior to acting upon them to establish their potential success and the most propitious time to perform them. Diviners and prophets would frequently undergo states of ecstatic possession to establish contact with the world of unseen powers. 
Page 5 of 7

It was from around the seventeenth century, influenced by dramatic developments in social, intellectual and economic life, that ideas about uncertainty, human agency and the future significantly modified the extreme determinism of the middle ages and prepared for the development of the concept of risk and allowing for the 'colonisation of the future' [33]. Reith speaks of the secularisation of chance whereby chance became autonomous and an ontological category in its own right. Stripped of its sacred and metaphysical attributes, it developed into a secular tool of scientific investigation [13].

'In a climate favorable to the scientific calculation of probability, chance came to indicate, not the favor of the gods, but an absence of knowledge. From being a sacred, it now became an epistemological, category. However, as we shall see, it was a long time even after it had emerged as a distinct secular category before it finally shed the last vestiges of its earlier religious meaning, and it was only when it was thoroughly secularized into a I meaningless' determinism in the nineteenth century that a path was cleared for its emergence as a genuine part of the world. By the twentieth century, chance had been stripped of its sacred and metaphysical attributes to become a secular tool of scientific explanation, so that what were once regarded as divine laws came to be understood as statistical probabilities. For the first time, chance became radically autonomous, an ontological category in its own right.'

No longer was chance conflated with the will of the gods or divine providence, but rather it was discussed in the language of science: odds, probability and statistics.

The dynamic merchant class and their trade concerns developed a new conception of the future that allowed for engagement with certainty. These changes were articulated through a new science of probability and statistics whereby attention to the future shifted from the short term to long term and from individual cases to general rules.

Hacking notes that historical records indicate that there was no real concept of probability in Europe before the mid-seventeenth century, although the use of dice and other randomizing objects was commonplace [34]. By the late nineteenth century it became possible to think of statistical patterns as explanatory in themselves, and to regard the world as not necessarily deterministic in character.

The idea of probability derived from two intellectual developments: a new pragmatic rationality that abandoned the idea of certainty and sustained and fruitful attempts to apply mathematics to new realms of experience. This new approach underscored the fact that, although singular events might appear to be random and unpredictable in the short term, over an extended period of time, they invariably fell into regular and $\mathrm{d}$ predictable patterns. While the mathematical elite progressed in their understanding randomness from the 17th to the 19th century, the public continued to depend upon practices such as divination in the hope of taming chance.

As Reith correctly asserts, probability theory transformed thinking about the future [31]. In The Empire of Chance, historians of science Gigerenzer et al. argue that statistical thinking has been "second to no other area of scientific endeavor" in its influence on "modern life and thought" [35]. Quantitative descriptions of risk associated with industrialization and technological change became part of the worldview of ordinary Americans. However the predictive capacity of probability and statistics was marred by one theoretical flaw, for although they could make generalizations about groups over time, they were unable to deal with small units in the present. Mohun argues that, although statistical representations describe past events (the history of a phenomenon), they are most often collected not by historians but by those interested in predicting or shaping the future [36]. As these practices spread from their origins in science and gaming theory, they have become one of the essential characteristics of what some sociologists have called "risk societies."

\section{Reith Asserts (p8)}

'The notions of risk and insurance embodied a calculative, longterm approach to uncertainty that signalled a radical new way of thinking about temporality. Probability's emphasis on the importance of the long term for making predictions was indicative of a worldview in which the uncertainties of the future were no longer regarded as acts of Divine intention, but rather as events to be understood through the concept of risk and managed through the practice of insurance.'

\section{Risk}

In western societies, risk now plays a central role in making the future more predictable and manageable and enabling the forensic investigation of the past. Risk assessment permits the identification and evaluation of uncertain events and attempts to diminish uncertainty in manageable limits. Accountability and risk run closely together. Douglas notes that not only does a culture need a common forensic vocabulary with which to hold people accountable but risk is a word that admirably serves the forensic needs of the new global culture [37]. As one example, in the area of health, epidemiologists map the incidence of disease and their spatial, temporal and social distribution providing a way of predicting and preventing future incidence. In other cultures, various forms of divination and ritual activity perform similar functions.

In contrast, modern scientific theories and knowledge that replace such belief systems are essentially limited in their utility. For Beck this uncertainty underpins contemporary concerns with risk:

'Risk society begins where tradition ends, when, in all spheres of life, we can no longer take traditional certainties for granted. The less we rely on traditional securities, the more risks we have to negotiate. The more risks, the more decisions and choices we have to make.

Risk is commonly defined in mathematical terms as the statistical probability of an outcome in combination with severity of the effect construed as a 'cost' that could be estimated in terms of money, deaths or cases of ill health. There is substantial evidence that people understand and judge risks in terms of emic, locally defined, values and concerns rather than in terms of science [38]. Furthermore they do not always make rational decisions about risks from a point of view of scientific risk assessment definitions of rationality [39].

Decisions about risk and management of risk are always socially embedded, shaped by culturally based notions about the state of the world, what the world consists of and the way it works [40,41]. Thus culture is crucial to risk perception. In social anthropology it has generally been taken for granted that what is to be considered a 'risk' depends entirely on cultural settings and assumptions; risks are culturally defined and selected. Risk perception is socially constructed and I would add so is accountability.

Douglas's interest in risk in industrial societies evolved from her work in the 1960s on pollution and dangers in tribal societies. As she states: "... risk is not only the probability of an event but also the probable magnitude of its outcome and everything depends on the 
Page 6 of 7

value that is set on the outcome. The evaluation is a political, aesthetic and moral matter."

In her view different individuals and different communities, might assess a risk more or less seriously because they value the consequences differently-they value differentially what is being harmed, who is doing the harm and who is responsible in any other way. Thus, the identification of a threat or danger, and the appraisal of its possible consequences, are inherently moral and depend on its cultural charge. More than this, the production of knowledge about risk creates a capacity to act according to principles, responsibility and accountabilities; more and more, risk carries connotations of accountability and blame [41]. However one lesson from crossnational research is that perception of risks is both uniform and variable; we find similarities as well as differences. Cross-national results demonstrate similarities and differences [42]. Asa Boholm argues that since interests invariably diverge - among individuals and more importantly among social groups, corporations, and organizations - issues of risk and safety have become increasingly political and controversial [3].

Cultural theory views risk as shaped by social and cultural processes rather than deriving from the thoughts, intentions and strategies of individuals. According to this perspective, the most important predictors influencing what people fear or do not fear are not individual cognitive processes such as the perception of threats to health or feelings of uncontrollability (as stated in psychometric research), but socially shared worldviews - so-called cultural biases that determine the individual's perceptions $[43,44]$. Cultural theorists argue that social debates about risks cannot be simply reduced to concerns about safety and demonstrate instead how they are inseparable from issues relating to power, justice and legitimacy. Douglas furthermore accounts for different risk perceptions in terms of a grid/group typology.

One major critique of the risk and culture approach pertains to the reduction of social risk-perception to the categories of cultural bias used. Assumptions about risk perception are far more complex and dynamic than the categories of the culture of risk approach imply: "Individual experiences of the social processes of risk perception may lead them to adopt a broad range of unclear or contradictory views about the magnitude of hazards $[45,46]$. Any attempt to mask the complexity of the social experience of risk perception in rigid conceptual abstractions may lead us further away, rather than towards a more intimate understanding of the day-to-day reality in which people recognize and negotiate with 'hazards' as 'risks' [47].

\section{Risk and Taboo}

In contrast to Beck, cultural theory acknowledges that there are no differences in principal between models to explain misfortune in modern and traditional societies - they maintain classificatory separations amongst groups [9]. Douglas suggests that the terms risk and taboo could both be subsumed under the more encompassing term 'dangers'. Explanations in terms of 'risk' in modern society are held to fulfil the same social function as explanations in terms of destiny, supernatural agency or broken taboo in traditional societies. The phenomenon in traditional societies that has been particularly emphasized within cultural theory is taboo. In many traditional societies there exist strong beliefs that certain actions or objects in combination with others will produce catastrophic consequences. Taboo serves to maintain social structure. As one illustrative example among the Hima of South West Uganda, misfortune such as the illness of a cow necessitates explanations and immediately initiates a process of searching for agency and responsibility. Women should be separated from cattle lest they cause sickness among the latter. Taboo therefore reinforces the social order - gender divisions, social hierarchies, labor divisions and power relations - through suppressing actions that might lead to fission. A traditional community seeking cultural homogeneity uses sin or taboo to enforce cultural integration; those in sin or under taboo have violated collective codes [48].

Risk and taboo are structurally the same although there is a difference of degree. However there are significant differences. Taboo in traditional societies expresses fate, that is to say, certainty and is invoked post hoc an event, while risk in modern societies deals with (more or less) calculated uncertainty. As Boholm [3] asserts, it is precisely because risk stands for calculated uncertainty, a risk can be practically managed, reduced or increased, it could be taken or avoided, depending on one's own and others actions and motives.

\section{Conclusion}

Above I have examined various ways in which groups deal with uncertainty emphasizing the roles of witchcraft, magic and risk. We need to build on the previous work of Mary Douglas. It behooves anthropologists to further explore how these phenomena relate to issues of accountability and address their forensic implications.

\section{References}

1. Cooper E, Pratten D (2014). Ethnographies of uncertainty from Africa. Palgrave Macmillan pp: 1-108.

2. Haram L, Yamba CB (2009) Dealing with Uncertainty in Contemporary African Lives. Nordiska Afrikainstitutet p: 221.

3. Boholm A (2003) The Cultural Nature of Risk: Can there be an Anthropology of Uncertainty? Ethnos 68(2): 159-178.

4. Boholm A (2015) Anthropology and Risk. London. Routledge pp: 1-172.

5. Evans-Pritchard EE (1937) Witchcraft, Oracles and Magic among the Azande. Oxford Clarendon Press p: 558.

6. Turner VW (1969) The drums of affliction A study of religious processes among the Ndembu of Zambia. Africa 39: 91-93.

7. Douglas M (1993) Risk as a Forensic Resource. In: Burger EJ (ed.) Risk, Ann Arbor: University of Michigan Press.

8. Whyte S (1997) Questioning Misfortune: The Pragmatics of Uncertainty in Eastern Uganda. Cambridge University Press p: 274.

9. Beck U (1992) Risk Society: Towards a New Modernity. Sage.

10. Kluckhohn C (1942) Myths and rituals: A general theory. Harvard Theological Review 35: 45-79.

11. Keesing R (1976) Cultural Anthropology: A Contemporary Perspective. New York: Holt, Rinehart and Winston.

12. Bourdieu P (2000) Konstens regler. Stehag: Symposium.

13. Reith G (1999) The Age of Chance: Gambling and Western Culture. Routledge.

14. Desjarlais RR (1997) Shelter blues: Sanity and selfhood among the homeless. University of Pennsylvania Press.

15. Capps L, Ochs E (1996) Constructing panic: The discourse of agoraphobia. American Ethnologist 38: 563-566.

16. Good BJ (1993) Medicine, Rationality, and Experience: An Anthropological Perspective: The Lewis Henry Morgan Lectures. Cambridge University Press. pp: 135-165.

17. Jenkins R, Jessen H, Steffen V (2005) Matters of Life and Death:The control of uncertainty and the uncertainty of control. København: Museum Tusculanum 2: 9-29. 
18. Tjørnhøj-ThomsenT (2005) Close encounters with infertility and the procreative technology. Managing uncertainty. Ethnographic studies of illness, risk and the struggle for control. pp: 71-91.

19. Bledsoe CH (2002) Contingent Lives: Fertility, Time, and Aging in West Africa. University of Chicago Press p: 416.

20. Ashforth A (2005) Witchcraft, Violence, and Democracy in South Africa. University of Chicago p: 376.

21. Scarre G, Callow J (2001) Witchcraft and Magic in Sixteenth- and Seventeenth-Century. Europe. Palgrave pp: 1-112.

22. Comaroff J, Comaroff JL (1999) Occult Economies and the Violence of Abstraction: Notes from the South African Postcolony. American Ethnologist 26: 279-303.

23. Comaroff J, Comaroff JL (2001) Millenial Capitalism and the Culture of Neoliberalism. Duke University Press p: 336.

24. Moore H, Sanders TD (2001) Magical interpretations, material realities: modernity, witchcraft and the occult in post-colonial Africa. LSE Research p: 253.

25. Geschiere P (1997) The Modernity of Witchcraft: Politics and the Occult in Postcolonial Africa. The Journal of Modern African Studies 37: 311.

26. Parish J (2010) Circumventing Uncertainty in the Moral Economy: West African Shrines in Europe, Witchcraft and Secret Gambling. African Diaspora 3: 76-92.

27. Ainslie A (2014) Harnassing The Ancestors: Mutuality, Uncertainty AND Ritual Practice In The Eastern Cape Province, South Africa. Africa 84: 530-552.

28. Buyandelgeriy M (2007) Dealing with uncertainty: Shamans, marginal capitalism, and the remaking of history in postsocialist Mongolia. American Ethnologist 34: 127-147.

29. Pollnac RB, Poggie JJ (1988) The structure of job satisfaction among New England fishermen and its application to fisheries management policy. American Anthropological Association 90: 888-901.

30. Hacking I (1975) The Emergence of Probability, Cambridge, Cambridge University Press.

31. Reith G (2004) Uncertain times: The notion of "risk" and the development of modernity. Time and Society 13: 383-402.

32. Flaceliere R (1965) Daily Life in Greece at the time of Pericles. Macmillan p: 310 .

33. Hagerstrand T (1985) Time-geography: Focus on the Corporeality of Man, Society, and Environment. The Science and Praxis of Complexity pp: 193-216.
34. Hacking I (2006) The Emergence of Probability. Cambridge: Cambridge University Press p: 246.

35. Gigerenzer G, Swijtink Z, Porter T, Daston L, Beatty J, et al. (1990) The empire of chance. How probability changed science and everyday life. Cambridge University Press p: 360.

36. Mohun A (2005) On the frontier of The Empire of Chance: statistics, accidents, and risk in industrializing America. Sci Context 18: 337-357.

37. Douglas M (1992) Risk and Blame: Essays in Cultural Theory. London: Routledge.

38. Stoffle RW, Traugott MW, Stone JV, McIntyre PD, Jensen FV, et al. (1991) Risk Perception Mapping: Using Ethnography to Define the Locally Affected Population for a Low-Level Radioactive Waste Storage Facility in Michigan. American Anthropologist 93: 611-635.

39. Renn O, Rohrmann B (2000) Cross-Cultural Risk Perception Research: State and Challenges. Cross-Cultural Risk Perception 13: 211-233.

40. Purcell K, Clarke L, Renzulli L (2000) Menus of choice: the social embeddedness of Decisions Cohen M J Risk in the Modern Age.

41. Douglas M, Wildavsky A (1982) Risk and culture: an essay on the selection of technical and environmental dangers. Yale Law Journal.

42. Kleinhesselink RR, Eugene AR (1991) Cognitive Representations of Risk Perceptions: A Comparison of Japan and the United States. Journal of Cross-Cultural Psychology 22: 11-28.

43. Wildavsky A, Dake K (1990) Theories of risk perception: who fears what and why? Daedalus. The MIT Press 119: 41-60.

44. Dake K (1992) Myths of Nature - Culture and the Social Construction of Risk, Journal of Social Issues 48: 21-37.

45. Renn O, Burns W, Kasperson RE, Kasperson JX, Slovic P (1992) The Social Amplification of Risk: Theoretical Foundations and Empirical Applications. Journal of Social Issues 48: 137-160.

46. Boholm A (1996) Risk perception and social anthropology: critique of cultural theory. Ethnos 61: 64-84.

47. Morgan D, Wilkinson I (2001) The Problem of Suffering and the Sociological Task of Theodicy. European Journal of Social Theory 4: 199-214.

48. Arnoldi J (2009) Risk: An Introduction. Cambridge, UK/Malden, MA: Polity pp: 190-203. 